\title{
TESTING THE SUITABILITY OF THE EXTRUDED POLYSTYRENE (STYRODUR) APPLICATION IN THE TRACK SUBSTRUCTURE
}

\author{
Libor IŽvolt, Peter Dobeš**, Martin MeČÁr \\ University of Žilina, Faculty of Civil Engineering, Department of Railway Engineering and Track Management, \\ Univerzitná 8215/1, 01026 Žilina, Slovakia \\ * corresponding author: peter.dobes@uniza.sk
}

\begin{abstract}
Extruded polystyrene (XPS) and its excellent thermal insulation properties have been known for over 60 years. Due to its thermal, mechanical, but also deformation properties, XPS has a universal application, not only in the construction industry. This paper presents the results of the first series of experimental measurements of the deformation resistance of the sub-ballast layers with a built-in XPS thermal insulation layer and the sub-ballast layers with a standard structure (crushed aggregate sub-ballast layer). The aim of the first series of experimental measurements was to determine the impact of placing the XPS layer at the subgrade surface level (deformation resistance of subgrade surface $E_{0}=$ approx. $10 \mathrm{MPa}$ or $30 \mathrm{MPa}$ ) on the deformation resistance of the sub-ballast layers and then to determine the necessary thickness of the sub-ballast layer in relation to the required deformation resistance at the sub-ballast upper surface. Experimental measurements carried out so far show that the application of XPS boards in the sub-ballast layers has almost no or minimal effect on its deformation resistance. Since XPS boards have significantly better thermal technical properties compared to crushed aggregate, considerable savings of this material can be achieved in areas with unfavorable climatic conditions (high values of air frost index).
\end{abstract}

KEYwORDS: Railway track, track substructure, extruded polystyrene, static load tests, deformation resistance.

\section{INTRODUCTION}

An important prerequisite for a quality design of the railway track structure, determined by the requirements for high-quality track layout and geometry, is its sufficient resistance to traffic and non-traffic loads. The track substructure must have the ability to receive a defined long-term traffic load from the track skeleton and non-traffic load (effects of climatic influences) without harmful deformations during the whole year. It can exhibit these properties only if it is designed with sufficient dimensions and built from quality building materials of the required characteristics, which guarantee adequate resistance to individual impacts of traffic (static and dynamic) and non-traffic (water or snow and frost) load [1].

At present, in the design of the railway track construction, it is necessary to consider not only highquality building materials of the required physicalmechanical and thermal-insulating properties but also to take into account the economic costs and environmental impact of these building materials. Partial or complete replacement of conventional building materials by materials with better thermal-technical properties (low water absorption and hence low thermal conductivity), but also suitable physical-mechanical properties (high permeability and low humidity, suitable grain size and high deformation resistance) results in a thickness reduction of the structural sub-ballast layers. In this way, it also decreases the amount of standard building materials for the establishment of the sub-ballast layer (currently mostly crushed aggregate), or it can possibly save financial resources for the installation of a sufficiently deformable and heat-insulating track substructure.

One of the thermal insulating materials that can be applied in the structural composition of the subballast layers is extruded polystyrene (XPS). The first polystyrene was made from natural resin by German physician Eduard Simon in 1839, but almost a century later, German organic chemist Hermann Staudinger realized that the isolated chemical was, in fact, a plastic polymer composed of long chains of styrene molecules, of which the name polystyrene was born. In 1937, polystyrene was introduced by Dow Chemical Co. to the US market for commercial purposes under the Styrofoam (EPS) brand. In 1953, Herman Staudinger was awarded the Nobel Prize for Chemistry, specifically for a research of polymers. The best-known form of expanded polystyrene packaging (XPS) was launched one year later (1954) [2]. In Europe, specifically in Austria, production of EPS under the Styropor trademark began in 1953. In 1990, production was expanded to include the XPS production, until then, the XPS was imported into Austria [3].

Abroad, thermal insulation materials such as EPS or XPS are applied to the railway track with the conventional type of railway superstructure (gravel su- 
perstructure), mostly at the sub-ballast upper surface, i.e. directly below the track ballast layer [4-6], or below the ballastless track structure [7, 8, in the case of unconventional railway superstructure. Placing the XPS at the bottom of sub-ballast layers has several drawbacks, namely:

- it must withstand significant traffic loads,

- it is worn due to a considerable contact stress with the ballast bed material,

- the track substructure may freeze from the side, especially in the case of a railway line in the embankment.

The authors' workplace - the Department of Railway Engineering and Track Management (DRETM) has been long involved in monitoring the impact of various building materials (gravel, liapor-concrete, foam concrete, styrodur) built in the sub-ballast layers to improve their thermal-technical 9] and deformation characteristics [10 12. Due to the aforementioned disadvantages of placing the XPS on the sub-ballast layers, the experimental workplace at DRETM started to test placing the XPS on the subgrade surface level. This level is particularly weak in the case of a subgrade surface consisting of fine-grained soils, it is the weakest link in the entire track substructure with the conventional track superstructure, not only in relation to traffic but also the non-traffic load.

The aim of the first series of experimental measurements was to determine the impact of placing the XPS layer at the subgrade surface level (deformation resistance of subgrade surface $E_{0}=$ approx. $10 \mathrm{MPa}$ or $30 \mathrm{MPa}$ ) on the deformation resistance of the subballast layers and then to determine the necessary thickness of the sub-ballast layer in relation to the required deformation resistance at the sub-ballast upper surface.

\section{Characteristics of Structures AND METHODOLOGY OF THE EXPERIMENTAL MEASUREMENTS}

This part of the paper presents the properties of the tested structures and the test methods for the verification of the deformation resistance of the sub-ballast layers with the built-in layer of extruded polystyrene (XPS), or without the XPS layer.

\subsection{Characteristics OF The tested STRUCTURES}

The extruded polystyrene (XPS) is produced from materials similar to the EPS but by a process known as extrusion. This is a manufacturing process in which the melt of crystalline polystyrene is extruded while the foaming agent is saturated. By releasing the pressure at the end of the extrusion tube, the material is filled, which then forms the insulating boards. Thus, the XPS manufacturing process has a major influence on its properties which are relatively different from other types of polystyrene. Extruded polystyrene is also produced with a modified edge when a half-groove is applied on the edge of the board. Thanks to this, the adjoining boards can be connected more easily and the heat loss of the structure in which they are built can be reduced.

In the construction industry, the extruded polystyrene is mostly used in the form of thermal insulation boards. Compared to other types of polystyrene boards, the mechanical resistance of the XPS is many times higher, it can withstand loads of $300 \mathrm{kPa}$ or more. Because the XPS exhibits a high impact and pressure resistance, it is used to isolate the areas that must withstand high compressive loads as well as mechanical loads. It is also important that, in addition to the conventional load, the XPS is resistant to water, mold, rodents, etc. Since XPS is also resistant to rotting and, compared to the conventional EPS, it has completely closed pores [13, so its application can be very suitable at points of contact with soil thanks to a good thermal insulation.

For the purpose of monitoring the impact of various thermal insulation materials in the track structure on its thermal regime and also deformation resistance, the DRETM experimental workplace [9] was built on the campus of the University of Žilina (UNIZA). One part of this experimental workplace is also an experimental field (Fig. 1), which serves to test the deformation characteristics of the structural sub-ballast layers.

The experimental field in question consists of two segments (A, B), where Segment $A$ represents the standard track substructure $(0 / 31.5 \mathrm{~mm}$ crushed aggregate sub-ballast layer) and the Segment $B$ represents the modified track substructure (crushed aggregate sub-ballast layer, fr. $0 / 31.5 \mathrm{~mm}+$ extruded polystyrene boards placed on the subgrade surface on the leveling sand layer).

Experimental measurements of the deformation resistance of the sub-ballast layers were performed in two stages. In the first stage of measurements, both segments of the experimental field were characterized by a lower deformation resistance of the subgrade surface, whose static deformation modulus $E_{0}=10 \pm 2 \mathrm{MPa}$. In the second stage of measurements, the deformation resistance of the subgrade surface was increased by its modification (grain change) - mechanical stabilisation. The deformation resistance of the modified subgrade surface reached the value of the static modulus of deformation $E_{0, \bmod }=30 \pm 2 \mathrm{MPa}$ in both segments of the experimental field, which coincidentally is the required value of the deformation resistance of the subgrade surface on existing lines for $S Z 4$ speed zone (120 km.h ${ }^{-1}<V \leq 160 \mathrm{~km} \cdot \mathrm{h}^{-1}$ ) according to [14]. In both construction cases, the Geofiltex 63/20 T separating geotextile was placed on the subgrade surface or the modified subgrade surface.

In segment B, $30 \mathrm{~mm}$ thick sheets of extruded polystyrene (STYRODUR $2800 \mathrm{C}-8$ pieces with dimensions $1250 \times 600 \mathrm{~mm}$ ) laid on the $50 \mathrm{~mm}$ thick 

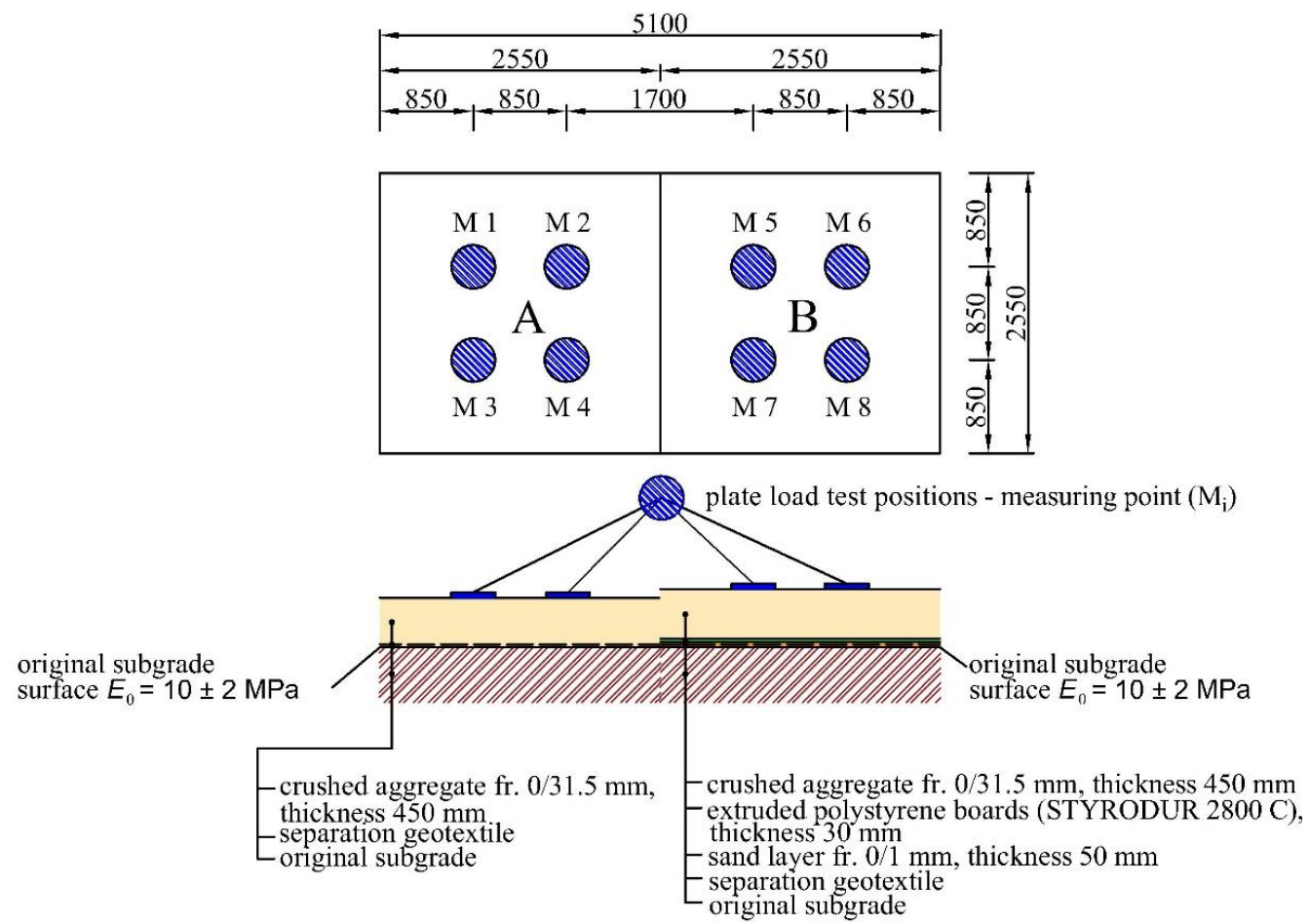

FiguRE 1. Experimental field $-1^{\text {st }}$ stage of experimental measurements.

\begin{tabular}{|c|c|c|}
\hline \multicolumn{3}{|c|}{5100} \\
\hline 2550 & & 2550 \\
\hline $850-850$ & 1700 & 850 \\
\hline
\end{tabular}
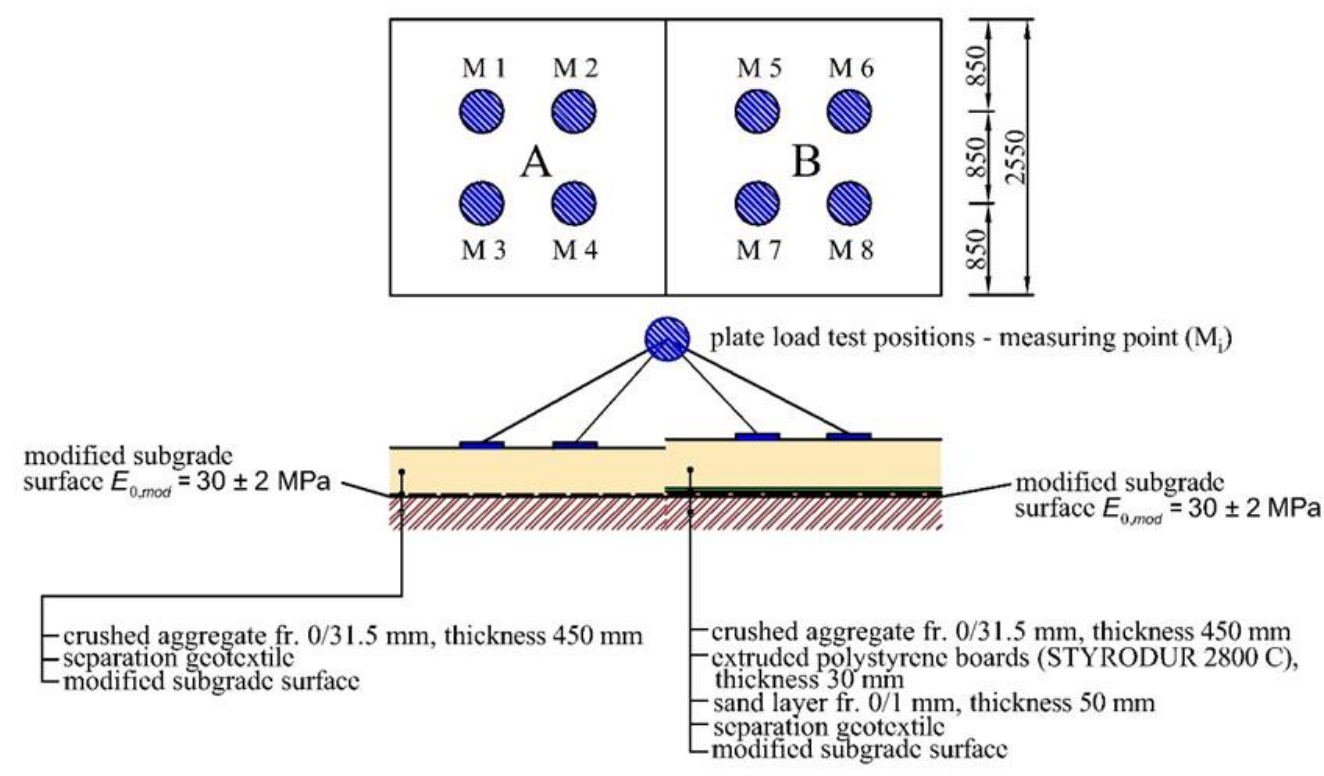

FiguRE 2. Experimental field $-2^{\text {nd }}$ stage of experimental measurements. 


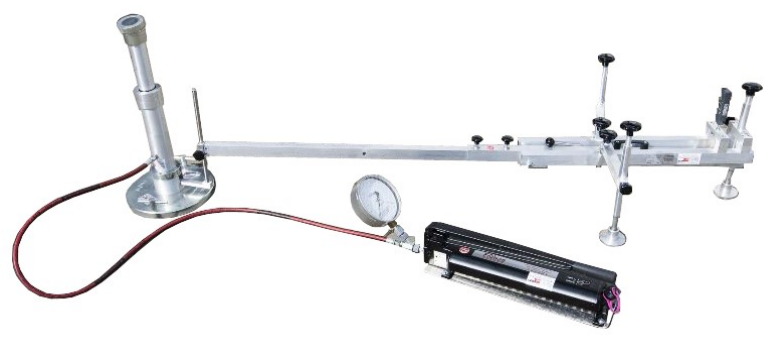

Figure 3. Static plate load test equipment [15].

sand leveling layer, were applied. In both phases of experimental measurements and for both segments, the sub-ballast layer was established from the crushed aggregate fr. $0 / 31.5 \mathrm{~mm}$, which was compacted with the aid of a vibration plate in such a technological way that its construction thicknesses of $150 \mathrm{~mm}, 300 \mathrm{~mm}$ and $450 \mathrm{~mm}$ were gradually achieved.

The structural composition of the experimental field with segments $\mathrm{A}$ and $\mathrm{B}$, with the location of the performed static load tests, are demonstrated in Fig. 1 and Fig. 2,

\subsection{Characteristics of Determining the DEFORMATION RESISTANCE OF SUB-BALLAST LAYERS}

The determination of the deformation resistance (static modulus of deformation) of the tested structural composition of the sub-ballast layers was conducted within the experimental measurements using the static plate load test equipment at the DRETM experimental field (Fig. 3).

The static plate load tests (PLT) at the sub-ballast upper surface of the experimental field (Segment A and Segment B) were performed according to the methodology outlined in the directive [16. In the process of performing the individual static load tests, a rigid circular plate of $300 \mathrm{~mm}$ diameter was pressed in two load cycles. The maximum contact stress used was $0.20 \mathrm{MPa}$ for both load cycles (standard stress used on the Slovak Railways lines for the sub-ballast layers). The measured variable was the static modulus of deformation $E_{s i}$, which was determined separately from the first and second load cycle. According to the methodology presented in [16], the value of the modulus of deformation obtained from the second load cycle is always decisive. The compaction quality of the material incorporated into the structural layer is expressed according to [17] from the ratio of the deformation moduli determined in the first and second load cycle $\left(E_{\text {def } 2} / E_{\text {def } 1}\right)$.

The static modulus of deformation $E_{s i}$ was determined according to the relation:

$$
E_{s i}=\frac{1.5 \cdot p \cdot r}{y}
$$

where: $E_{s i}$ - static modulus of deformation of the $\mathrm{i}^{\text {th }}$ structural layer, (MPa); $p$ - specific pressure applied to the plate, $(\mathrm{MPa}) ; r$ - radius of the load plate, $(\mathrm{m})$; $y$ - the total average settlement of the load plate determined in the second cycle, $(\mathrm{m})$.

The measurement of the values of static modulus of deformation $E_{s i}$ at the level of individual structural layers of the tested structures was carried out in both stages of experimental measurements at the subgrade surface level, or a modified subgrade surface level, at the level of XPS boards and subsequently at the level of each partial structural layer of the sub-ballast layers.

For each construction layer of Segment A or Segment B of the experimental field, a series of 4 static plate load tests was performed, always at the same location indicated as the measurement point $M_{i}$. Measurement points M 1 to M 4 (see Fig. 1) are located in the Segment A of the experimental field (non-XPS segment in the sub-ballast layers) and the measurement points M 5 to M 8 are located in Segment B (a segment with XPS embedded in the sub-ballast layers) (see Fig. 2).

\section{Results of EXPERIMENTAL MEASUREMENTS}

Fig. 4 shows the measured values of the static modulus of deformation $E_{s i}$ at the level of the individual sub-ballast layers of the experimental field for both segments within the $1^{\text {st }}$ stage (lower deformation resistance/bearing capacity of the subgrade surface). Fig. 4 demonstrates a gradual increase in the deformation resistance of the sub-ballast layers as the thickness of the sub-ballast layer increases. It is also evident that the XPS boards placed on a leveling layer of sand and a low deformation subgrade surface $\left(E_{0}=10 \pm 2 \mathrm{MPa}\right)$ had a minimal effect on the resulting (equivalent) deformation resistance of the sub-ballast layers (at the level of sub-ballast layers) of the tested structure in the experimental field.

Fig. 5 shows the measured values of the static modulus of deformation $E_{s}$ at the level of the individual sub-ballast layers of the experimental field for both segments within the $2^{\text {nd }}$ stage. In this case, a higher value of deformation resistance $\left(E_{0, \bmod }=30 \pm 2 \mathrm{MPa}\right)$ was achieved at the level of the modified subgrade surface. Fig. 5 also demonstrates that the extruded polystyrene boards placed on the leveling layer of sand caused a decrease in the deformation resistance of about 7 to $8 \mathrm{MPa}$, as compared to the values obtained for a modified subgrade surface. Consequently, this decrease of the deformation resistance also had an impact on the achieved partial or total deformation resistance of the tested sub-ballast layers. Since the decrease of the deformation resistance determined on the surface of extruded polystyrene boards was observed only in the case of the modified subgrade surface, it is possible to assume that, in this case, the extruded polystyrene board material occurred between two solid surfaces (a deformation-resistant subgrade surface and a circular plate of the static load 

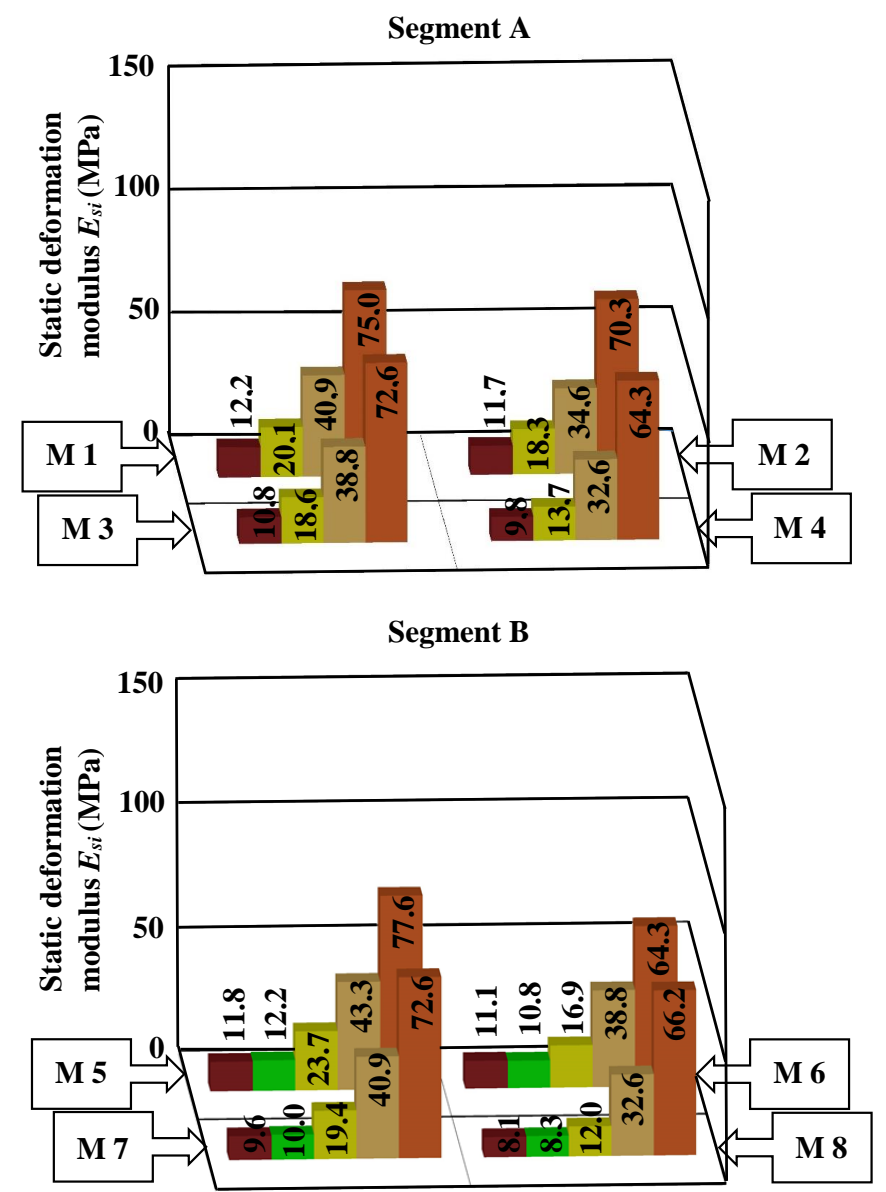

Original subgrade surface

Surface of the extruded polystyrene board, thickness $30 \mathrm{~mm}$

Surface of the crushed aggregate layer - 1. layer, thickness $150 \mathrm{~mm}$

Surface of the crushed aggregate layer - 2. layer, thickness $300 \mathrm{~mm}$

Surface of the crushed aggregate layer - 3. layer, thickness $450 \mathrm{~mm}$

FiguRE 4. Measured values of static modulus of deformation $E_{s i}$ on the surface of individual structural sub-ballast layers - $1^{\text {st }}$ stage (lower deformation resistance of the subgrade surface).

equipment) and became more compressed. (In the case of the low deformation resistance of subgrade surface, the difference between the static modulus of deformation determined on the surface of the subgrade surface and extruded polystyrene was minimal.) In the case of a low deformation-resistant subgrade surface, the boards of extruded polystyrene were likely to be deformed at the same time as the subsoil on which they were laid, and therefore there was no significant compression.

It can be assumed that once the maximum compression of the extruded polystyrene boards in the sub-ballast layers due to operational load of the track (the weight of the overlaying construction layers including the track skeleton and trains) has been achieved, the impact of the XPS boards on the deformation resistance of sub-ballast layers will also be minimal. The compaction of the individual crushed aggregate layers was performed by a vibration plate, and the achieved values of compaction (the ratio between the achieved value of the static modulus of deformation in the $1^{\text {st }}$ and $2^{\text {nd }}$ load cycles) ranged from 1.4 to 1.8. These values are satisfactory since the maximum permissible value for the coarse-grained material according to [17] is 2.6. The compaction values at the subgrade surface level formed by the fine-grained material were in the range of 2.0 to 2.3. These values are also satisfactory since the maximum permissible value for the fine-grained material according to [17] is 2.5.

Fig. 66 shows the dependence of the sub-ballast layer thickness tsbl on the required value of the static deformation modulus $E_{s i}$ of the sub-ballast upper surface $\left(E_{s b l}\right)$ for the standard sub-ballast layers (sub-ballast layer formed only by crushed aggregate) with low deformation-resistant subgrade surface $E_{0}=$ approx. $10 \mathrm{MPa}$. In the case of an existing line located in the SZ4 speed zone $\left(120 \mathrm{~km} \cdot \mathrm{h}^{-1}<V \leq 160 \mathrm{~km} \cdot \mathrm{h}^{-1}\right)$, in order to achieve the required static modulus of deformation of the sub-ballast upper surface $E_{s b l} \geq 50 \mathrm{MPa}$ it would be necessary to design the sub-ballast layer 

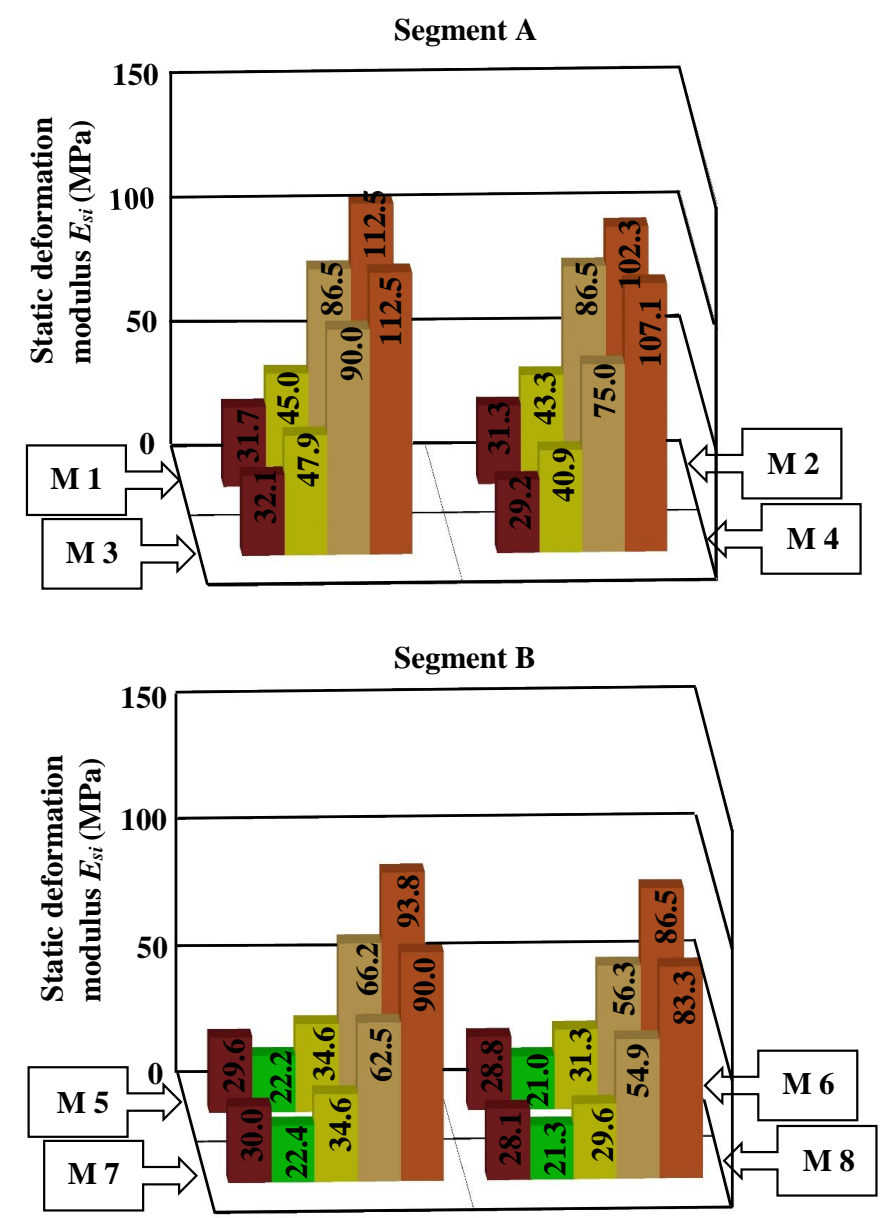

Modified subgrade surface

Surface of the extruded polystyrene board, thickness $30 \mathrm{~mm}$

Surface of the crushed aggregate layer - 1. layer, thickness $150 \mathrm{~mm}$

Surface of the crushed aggregate layer - 2. layer, thickness $300 \mathrm{~mm}$

Surface of the crushed aggregate layer - 3. layer, thickness $450 \mathrm{~mm}$

Figure 5. Measured values of static modulus of deformation $E_{s i}$ on the surface of individual structural sub-ballast layers $-2^{\text {nd }}$ stage (higher deformation resistance of the subgrade surface).

$400 \mathrm{~mm}$ thick. However, the same thickness of the sub-ballast layer would also have to be designed in the case of the modified structural composition of the sub-ballast layers. Here, in addition to the sub-ballast layer of crushed aggregate, the tested structure contains the XPS boards placed on the sand leveling layer (Fig. 7).

Fig. 8 shows the dependence of the thickness of the crushed aggregate sub-ballast layer on the required value of the static deformation modulus $E_{s i}$ of the sub-ballast upper surface $\left(E_{s b l}\right)$ for the standard structure of sub-ballast layers (sub-ballast layer of crushed aggregate only) and higher deformation resistance of the subgrade surface $E_{0}=$ approx. $30 \mathrm{MPa}$. In the case of an existing line located in the SZ4 speed zone $\left(120 \mathrm{~km} \cdot \mathrm{h}^{-1}<V \leq 160 \mathrm{~km} \cdot \mathrm{h}^{-1}\right)$, in order to achieve the required static modulus of deformation of the sub-ballast upper surface $E_{s b l} \geq 50 \mathrm{MPa}$, it would be necessary to design the sub-ballast layer only $200 \mathrm{~mm}$ thick. In the case of designing a modified structural composition of the sub-ballast layers (sub-ballast layer consisting of crushed aggregate and XPS boards), it would be desirable to design the sub-ballast layer of a construction thickness greater than $100 \mathrm{~mm}$ (Fig. 9).

\section{Conclusions}

Within the research of the Department of Railway Engineering and Track Management at the University of Žilina, a series of experimental measurements related to the assessment of the suitability of the application of XPS boards in the track substructure with the conventional superstructure (gravel superstructure) coacting with the sub-ballast layer of crushed aggregate fr. $0 / 31.5 \mathrm{~mm}$ were conducted.

The experimental test field was divided into Segment A (standard structure of sub-ballast layers, i.e. the sub-ballast layer of crushed aggregate) and Segment B (modified structure of sub-ballast layers, i.e. sub-ballast layer of crushed aggregate and XPS 


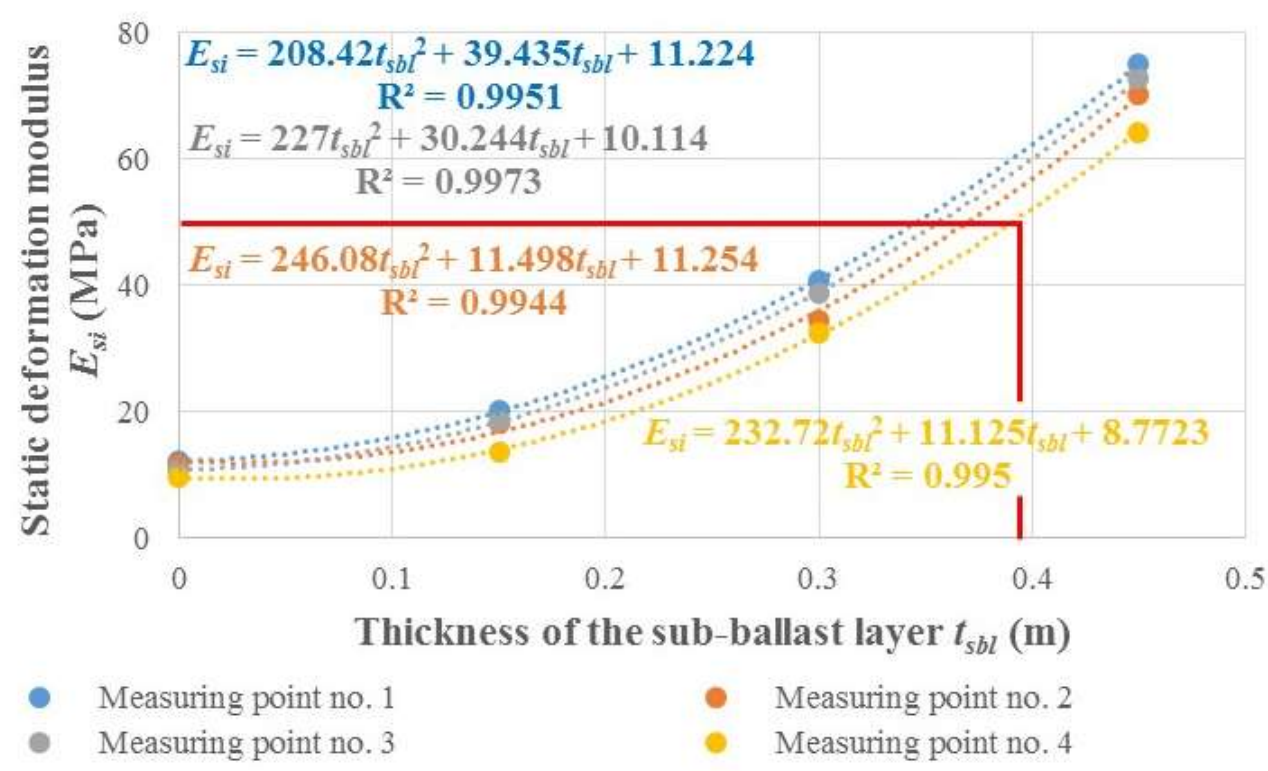

Figure 6. Dependence of the sub-ballast layer thickness $t_{s b l}$ on the required value of the static modulus of deformation $E_{s}$ (standard structure of sub-ballast layers, low deformation resistance of the subgrade surface - approx. $10 \mathrm{MPa}$ ).

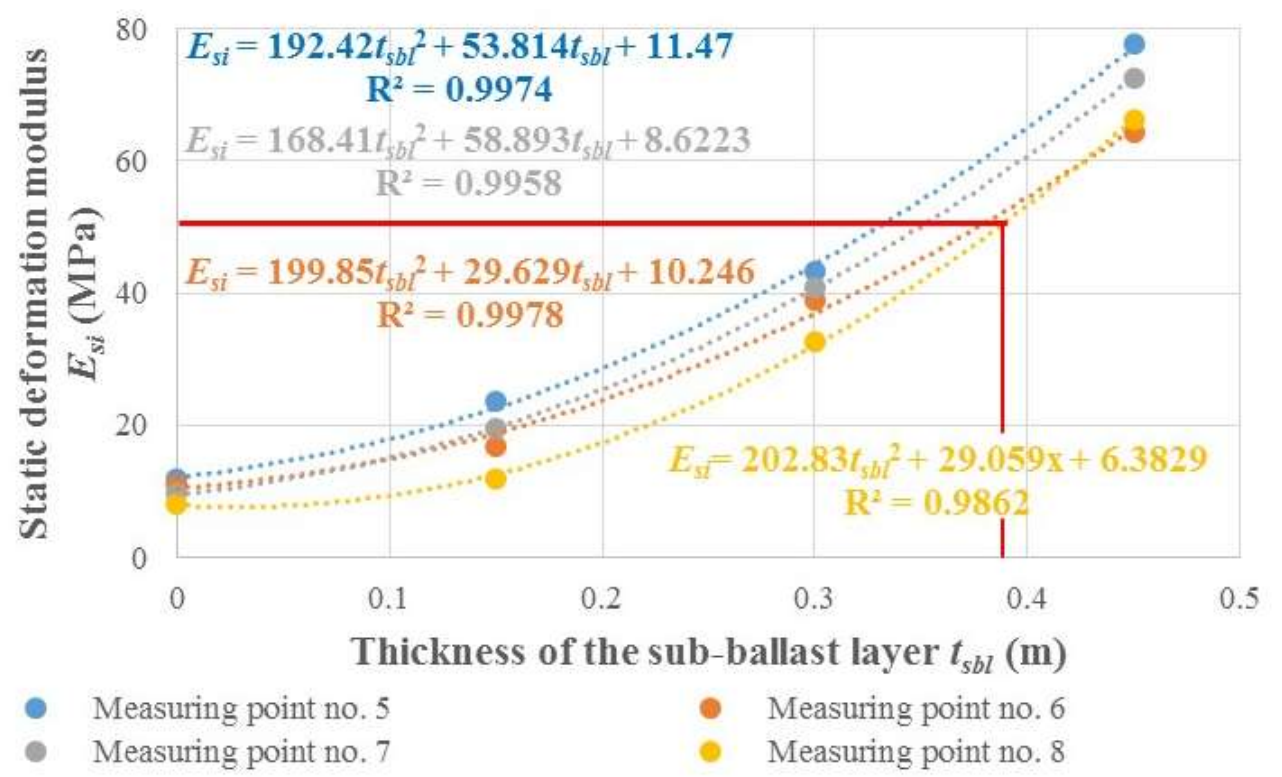

FiguRE 7. Dependence of the sub-ballast layer thickness $t_{s b l}$ on the required value of the static modulus of deformation $E_{s}$ (structure of sub-ballast layers with built-in XPS boards, low deformation resistance of the subgrade surface approx. $10 \mathrm{MPa}$ ). 


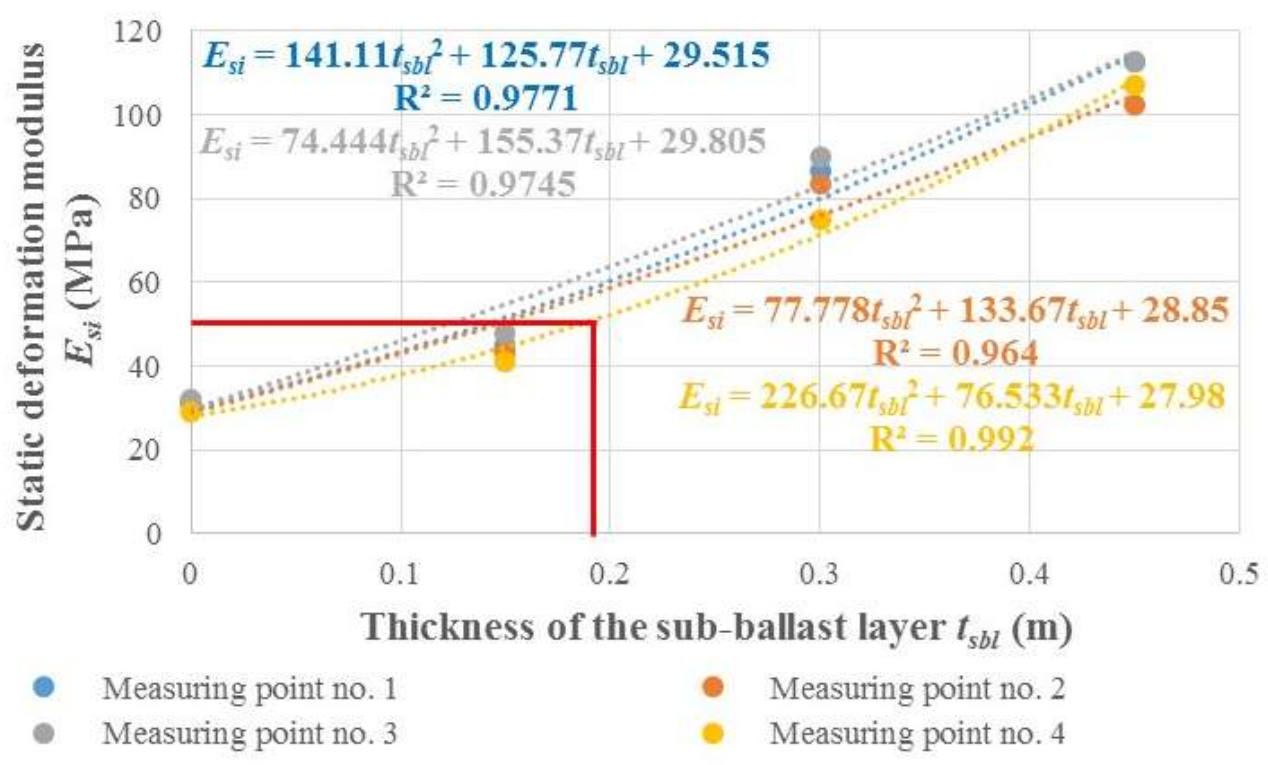

FiguRE 8. Dependence of the sub-ballast layer thickness $t_{s b l}$ on the required value of the static modulus of deformation $E_{s}$ (standard structure of sub-ballast layers, higher deformation resistance of the subgrade surface approx. $30 \mathrm{MPa})$.

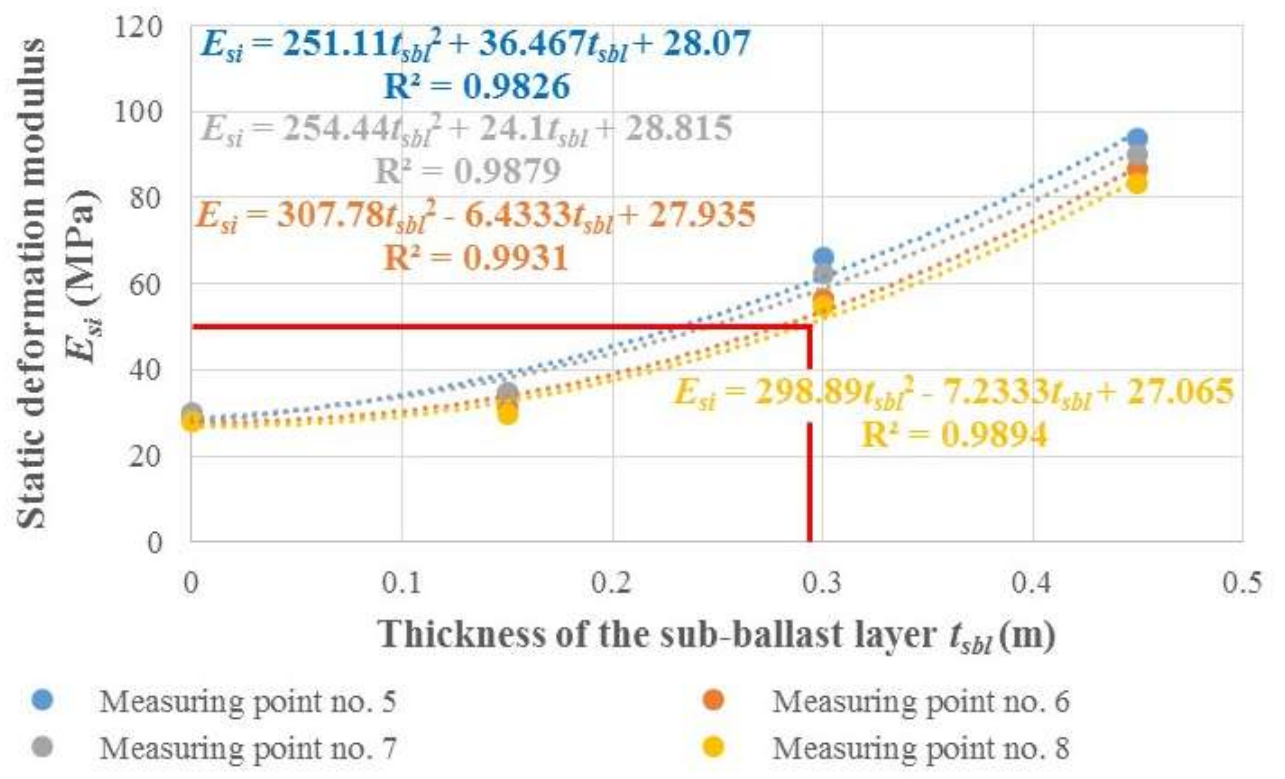

Figure 9. Dependence of the sub-ballast layer thickness $t_{s b l}$ on the required value of the static modulus of deformation $E_{s}$ (structure of sub-ballast layers with built-in XPS boards, higher deformation resistance of the subgrade surface approx. $30 \mathrm{MPa})$. 
boards). The impact of the built-in XPS boards on the deformation resistance of sub-ballast layers is apparent from Fig. 4 to Fig. 9.

Fig. 4, or Fig. 6 and Fig. 7 demonstrate that the application of the XPS boards in the sub-ballast layers has almost no effect on its deformation resistance in the case of a low deformation-resistant subgrade surface $\left(E_{0}=10 \pm 2 \mathrm{MPa}\right)$.

In the case of a more deformation-resistant subgrade surface $\left(E_{0, \bmod }=30 \pm 2 \mathrm{MPa}\right)$, the XPS boards in the sub-ballast layers cause a decrease in its deformation resistance, but it is assumed that after reaching the maximum compression of XPS boards caused by an operational load on the track (the weight of the overlaying structural layers including the track skeleton and the trains), their impact on the deformation resistance of sub-ballast layers will be negligible (Fig. 5. Fig. 8 and Fig. 9). Since the XPS boards have significantly better thermal technical properties compared to crushed aggregate (especially the thermal conductivity value, which is 50 times lower [18]), considerable savings of this material can be achieved in areas with unfavorable climatic conditions (high values of air frost index). A comparison of standard and modified structure of sub-ballast layer's design for other cases of deformation resistance of subgrade surface $\left(E_{0}=20 \mathrm{MPa}\right.$ or $40 \mathrm{MPa}$ - the second series of experimental measurements), for cyclic loading of sub-ballast layers and from the point of view of the non-traffic load will be subject to further experimental research at DRETM.

\section{ACKNOWLEDGEMENTS}

The presented results are partial results of solving the VEGA grant project 1/0084/20 "Numerical and experimental analysis of transition areas of objects of structures of railway superstructures and objects of formation substructure".

\section{REFERENCES}

[1] L. Ižvolt. Railway substructure - stress, diagnostics, design and implementation of body construction layers of railway subgrade (Scientific monograph). EDIS, 2008. Slovak.

[2] Isowall Group. A brief history of polystyrene. https://www.isowall.co.za/ a-brief-history-of-polystyrene/, 2019. Accessed: 3 October 2019.

[3] AUSTROTHERM: History. http://en.austrotherm. com/front_content.php?idcat $=155,2019$. Accessed: 3 October 2019.

[4] P. Addison, P. Lautala, T. Oommen, Z. Vallos. Embankment stabilization techniques for railroads on permafrost. In Proceedings of the 2016 Joint Rail Conference, pp. 1 - 9. 2016. DOI:10.1115/JRC2016-5731.

[5] A. Nurmikolu, P. Kolisoja. Extruded polystyrene (XPS) foam frost insulation boards in railway structures. In Proceedings of the 16th International Conference on Soil Mechanics and Geotechnical Engineering, pp. 1761 1764. 2006.
[6] Styrodur: Load-bearing and Floor Insulation. https://static1.squarespace.com/static/ 53f9d90ee4b0572e560769f8/t/ 54bbe72be4b0567044c061c0/1421600555419/ Styrodur+Floor+Application+Brochure.pdf 2019. Accessed: 3 October 2019.

[7] C. Esveld, V. Markine. Use of expanded olystyrene (EPS) sub-base in railway track design. IABSE Symposium Report pp. 33 - 38, 2003. DOI: $10.2749 / 222137803796329952$

[8] M. Madhkhan, M. Entezam, M. Torki. Mechanical properties of precast reinforced concrete slab tracks on non-ballasted foundations. Scientia Iranica 19(1):20 26, 2012. DOI:10.1016/j.scient.2011.11.037.

[9] P. Dobeš, L. Ižvolt, S. Hodás. Examining the influence of railway track routing on the thermal regime of the track substructure - experimental monitoring. In Proceedings of the 16th Scientific and Technical Conference Transport Systems Theory and Practice, pp. 201 - 209. 2019.

[10] L. Izvolt, P. Dobes, M. Mecar. Testing the suitability of the reinforced foam concrete layer application in the track bed structure. IOP Conference Series: Materials Science and Engineering 661:012014, 2019. DOI:10.1088/1757-899x/661/1/012014

[11] J. Vlcek, M. Drusa, W. Scherfel, B. Sedlar. Experimental investigation of properties of foam concrete for industrial floors in testing field. IOP Conference Series: Earth and Environmental Science 95:022049, 2017. DOI:10.1088/1755-1315/95/2/022049

[12] V. Valašková, J. Vlček, M. Drusa. Experimental and computational dynamic analysis of the foam concrete as a sub-base layer of the pavement structure. MATEC Web of Conferences 211:13002, 2018. DOI:10.1051/matecconf/201821113002

[13] URSA XPS: Insulation for a better tomorrow. https://cmt.ee/wp-content/uploads/2018/10/URSA_ XPS_intro_ENG.pdf 2019. Accessed: 3 October 2019.

[14] TNŽ 736312 - The design of structural layers of subgrade structures. Standard, Directorate General of Railways of the Slovak Republic, Slovakia, 2005.

[15] GEOLAB: In-situ and Lab Testing Equipment. https://geolab.com.pl/en/oferta/ grunty-sprzet-terenowy/

plyta-statyczna-vss-jednopunktowa/ plyta-statyczna-vss-1f, 2019. Accessed: 3 October 2019.

[16] Slovak Railway Regulation TS4 "Track substructure Appendix 6". Standard, Directorate General of Railways of the Slovak Republic, Slovakia, 2018.

[17] STN 736133 - Road Building. Roads embankments and subgrades. Standard, Slovak Office of Standards, Metrology and Testing, Slovakia, 2017.

[18] Styrodur: Technical Data. https://www2.basf.de/ basf2/img/produkte/kunststoffe/styrodur/ downloads2/en/styrodurtechnicaldata.pdf 2019. Accessed: 3 October 2019. 